\title{
Influência do nível de irradiância no crescimento, produção e composição química do óleo essencial de hortelã-do-campo (Hyptis marrubioides Epl.)
}

\section{Growth, production and chemical composition of the essential oil in hortelã-do-campo (Hyptis marrubioides Epl.) in function of the irradition level}

\author{
Juliana de Fátima Sales ${ }^{1 *}$; José Eduardo Brasil Pereira Pinto²; \\ Pedro Henrique Ferri ${ }^{3}$; Fabiano Guimarães Silva ${ }^{1}$; \\ Carolina Brom Aki de Oliveira ${ }^{3}$; Priscila Pereira Botrel ${ }^{4}$
}

\begin{abstract}
Resumo
No presente trabalho avaliou-se o nível de irradiância de 20,60 e 100\% de luz natural no crescimento, teor e a composição do óleo essencial de hortelã-do-campo (Hyptis marrubioides). O experimento foi conduzido no delineamento inteiramente casualizado, com vinte e cinco repetições por tratamento. Após 132 dias de cultivo analisou-se o crescimento da planta, o teor e a composição do óleo essencial. Em $100 \%$ de irradiância as plantas apresentaram menor altura, quando comparado aos tratamentos sombreados. A relação ramo/folha foi maior no nível de irradiância de $20 \%$. O número de ramos e o acúmulo de fitomassa foram maiores no nível de irradiância de $100 \%$. O teor de óleo essencial não foi influenciado pelos níveis de irradiância, mas o rendimento foi maior quando cultivadas a $100 \%$ de irradiância. A composição química do óleo essencial não apresentou alterações com os diferentes níveis de irradiância, exceto para o iso-3-tujanol e $\delta$-cadineno, que apresentaram maiores concentrações em plantas cultivadas respectivamente a 100 e $60 \%$ de irradiância. O componente majoritário do óleo essencial de $H$. marrubioides, independente dos níveis de irradiância foi o monoterpeno oxigenado cistujona $(37,78 \%)$, seguido pelos hidrocarbonetos sesquiterpênicos (E)-cariofileno (14,93\%), $\alpha$-copaeno $(11,03 \%)$ e $\sigma$-muuroleno $(9,60 \%)$.
\end{abstract}

Palavras-chave: Hyptis marrubioides, planta medicinal, óleo essencial

\begin{abstract}
In the present work, the level of irradiation of 20,60 and $100 \%$ of natural light on the growth, content and composition of the essnetial oil of "hortelã do campo" (Hyptis marrubioides) was evaluated. The experiment was conducted in the completely randomized design with twenty-five replicates per treatment. After 132 days of cultivation, plant growth and the content and compositoin of the essntial oil were investigated. At $100 \%$ of irradiation, the plants presented less height as compared with the shaded treatments. The ratio branch/leaf was higher at the level of irradiation of $20 \%$. It was found that in the full sunshine, the plants showed lower height as compared with the shaded treatments. The leaf/
\end{abstract}

\footnotetext{
Professores, Dr. Instituto Federal de Educação, Ciência e Tecnologia Goiano, Campus Rio Verde. E-mail: juliana.sales@pq.cnpq.br Professor, PhD. Departamento de Agricultura - UFLA. Lavras - MG.

3 Professores, Dr. Instituto de Química, Laboratório de Bioatividade Molecular - UFG. Cx. Postal 131, 740001-970 Goiânia, GO.

4 Discente de graduação. Bolsista de IC/CNPq - UFLA.

* Autor para correspondência
} 
branch ratio was higher at the lowest level of irradition of $20 \%$. The number of branches and the plant mass accumulation were greatest at the level of irradition of $100 \%$. The content of essential oil was not influenced by the levels of irradiation, but the yield was greater when grown at the level of $100 \%$ of irradiation. The chemical composition of the essential oil of Hyptis marrubioides did not present any alterations with the different levels of irradiation, except for $i s o$-3-tujanol and $\delta$-cadineno, which presented highest concentrations in plants grown, respectively at 100 and $60 \%$ of irradiation. The major component of teh essential oil of H. marrubioides, independent of the levels of irradiation was cistujona oxygenated monoterpene (37.78\%), followed by sequiterpenes hiydrocarbonetes (E)-cariofileno (14.93\%), $\alpha$-copaeno (11.03\%) and $\sigma$-muuroleno $(9.60 \%)$.

Key words: Hyptis marrubioides, medicinal plant, essential oil

\section{Introdução}

O gênero Hyptis Jacq. (Lamiaceae) inclui cerca de 300 espécies, de ampla ocorrência na América Tropical (HARLEY, 1988; WILLIS, 1973), sendo importante fonte de constituintes bioativos com efeito antimicrobianano, citotóxico e inseticida (KUHNT et al., 1995).

A luz influencia diretamente o crescimento e o desenvolvimento das plantas, causando alterações morfofisiológicas e, indiretamente, o teor e composição de metabólitos especiais (VALIO, 2001; VILELA; RAVETTA, 2000).

Diferentes espécies medicinais tem sidoestudadas com a finalidade de determinar a iluminação satisfatória para maximizar o rendimento de óleo essencial. A exemplo, tomilho (Thymus vulgaris L.), Lamiaceae, cultivado em maior nível de irradiância apresentou menor altura, brotos eretos com mais perfilhos, ramos e folhas mais grossos, maior área foliar, além de fitomassa seca da parte aérea e raízes. Em contraste, plantas cultivadas em menor intensidade de luz apresentaram crescimento prostrado, com folhas menos espessas, mais largas e coloração verde levemente pálida (LETCHAMO et al., 1994; LETCHAMO; GOSSELIN, 1995, 1996).

O presente trabalho objetivou avaliar os níveis de irradiância sobre o crescimento, produção e composição química do óleo essencial de hortelãdo-campo (Hyptis marrubioides).

\section{Material e Métodos}

\section{Cultivo da planta}

As plantas foram coletadas no município de

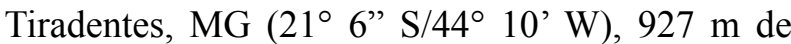
altitude, e identificadas pelo botânico Manoel Losada Gavilanes. A exsicata está depositada no herbário da Universidade Federal de Lavras, sob o código ESAL 13955.

A propagação do material realizada em setembro de 2003 foi feita por meio de estacas com $10 \mathrm{~cm}$ de comprimento em potes plásticos contendo substrato plantmax $^{\circledR}$, por 30 dias até o enraizamento. Após o enraizamento, as estacas com aproximadamente $20 \mathrm{~cm}$, foram transplantadas no Horto de Plantas Medicinais/DAG/UFLA ( $\left.21^{\circ} 14^{\prime} \mathrm{S} / 44^{\circ} 59^{\prime \prime} \mathrm{W}\right)$, a uma altitude de $919 \mathrm{~m}$, sob espaçamento de 1x1 m.

As plantas foram cultivadas por quatro meses sob três tipos de ambiente, caracterizados pela disponibilidade de radiação solar incidente, controlada por tela refletora comercial (Aluminet ${ }^{\circledR}$, 80 e $40 \%$ de interceptação da radiação solar) e em pleno sol.

\section{Condições de clima}

As condições climáticas foram obtidas na Estação Climatológica do Departamento de Engenharia Agrícola da UFLA, conforme descrito na Tabela 1. 
Tabela 1. Temperaturas médias diárias, precipitação e umidade relativa do ar durante o período de setembro de 2003 a janeiro de 2004.

\begin{tabular}{lccccc}
\hline \multicolumn{1}{c}{ Mês/ano } & Temperatura & Temperatura & Temperatura & Precipitação & Umidade \\
& Máxima $\left({ }^{\circ} \mathrm{C}\right)$ & Média $\left({ }^{\circ} \mathrm{C}\right)$ & Mínima $\left({ }^{\circ} \mathrm{C}\right)$ & $(\mathrm{mm})$ & relativa $(\%)$ \\
\hline Setembro/2003 & 28,3 & 20,5 & 14,9 & 13,7 & 64,2 \\
Outubro/2003 & 28,6 & 21,6 & 16,1 & 64,9 & 62,4 \\
Novembro/2003 & 28,2 & 21,8 & 12,3 & 154,5 & 73,3 \\
Dezembro/2003 & 28,8 & 23,1 & 18,6 & 238,8 & 77,3 \\
Janeiro/2004 & 28,2 & 22,0 & 17,7 & 190,5 & 75,5 \\
\hline
\end{tabular}

\section{Colheita}

Após 132 dias de cultivo, as folhas colhidas foram desidratadas em ausência de luz com auxílio de um desumidificador Arsec $160^{\circledR}$, durante sete dias, à temperatura média máxima de $28,4{ }^{\circ} \mathrm{C}$, mínima de $15,9^{\circ} \mathrm{C}$ e média de $22^{\circ} \mathrm{C}$. No momento da extração do óleo essencial as folhas foram submetidas à moagem em moinho com peneira de 10 mesh (Marconi ${ }^{\circledR}$ MA 680).

\section{Extração}

Cinqüenta gramas de fitomassa seca de folhas foram submetidas a hidrodestilação em $500 \mathrm{~mL}$ no aparelho Clevenger modificado por 50 minutos e o hidrolato coletado extraído com diclorometano, na proporção de $1 / 4$ do total obtido, em três vezes. Como dessecante foi adicionado sulfato de magnésio anidro durante 24 horas, seguido de filtração, seco a $35^{\circ} \mathrm{C}$ e transferido para um frasco de vidro envolvido com papel alumínio. $\mathrm{O}$ frasco foi mantido em capela em temperatura ambiente para evaporar o diclorometano, até peso constante, determinando-se o teor de óleo essencial.

A partir do acúmulo de fitomassa seca de folhas e do teor de óleo essencial, calculou-se o rendimento médio de óleo essencial por planta.

\section{CG-MS}

A análise da composição do óleo essencial foi realizada em um cromatógrafo a gás acoplado a espectrômetro de massas (Shimadzu QP5050A), nas seguintes condições operacionais: coluna capilar de sílica fundida, modelo CBP-5 (30 m de comprimento $\times 0,25 \mathrm{~mm}$ de diâmetro interno $\times 0,25 \mu \mathrm{m}$ de espessura do filme em $5 \%$ de fenilmetilpolisiloxano) (Shimadzu, Japão), com fluxo de $1 \mathrm{ml} \cdot \mathrm{min}^{-1}$ de Hélio como gás de arraste.; aquecimento com temperatura programada $\left(60^{\circ} \mathrm{C}\right.$ com um gradiente de $3^{\circ} \mathrm{C} \cdot \mathrm{min}^{-1}$ até $240^{\circ} \mathrm{C}$ e, em seguida, com um gradiente de $10^{\circ} \mathrm{C}$. $\min ^{-1}$ até $270^{\circ} \mathrm{C}$, mantendo-se uma isoterma de 7 min, com um tempo total de corrida de $70 \mathrm{~min}$ ). A energia de ionização do detector foi de 70 e V, sendo o volume de injeção da amostra de $0,5 \mu l$ diluídas em diclorometano (grau ultra-resíduo, Baker, EUA) e uma razão de injeção de 1:20. As temperaturas do injetor e do detector foram mantidas em $220{ }^{\circ} \mathrm{C}$ e $240^{\circ} \mathrm{C}$, respectivamente. A análise foi conduzida no modo varredura, a uma velocidade de 1,0 varredura. $\mathrm{s}^{-1}$, com um intervalo de massas de 40-400 $\mathrm{m} / \mathrm{z}$. A análise quantitativa foi obtida pela integração do cromatograma total de íons (TIC). A identificação dos constituintes foi realizada por comparação, automática e manual, dos espectros de massas com os das bibliotecas NIST/EPA/NHI (1998), por comparação dos espectros de massas e Índices de Retenção (IR) com os da literatura (ADAMS, 2001) e co-injeção com padrões autênticos. Os Índices de Retenção foram calculados através da co-injeção com uma mistura de hidrocarbonetos, $\mathrm{C}_{8}-\mathrm{C}_{32}$ (Sigma, EUA), e com aplicação da equação de Van Den Dool e Kratz (1963). 


\section{Avaliação do crescimento}

O crescimento foi avaliado medindo área foliar, comprimento da parte aérea $(\mathrm{m})$, número de ramos na altura do colo, acúmulo de fitomassa seca de folhas (g) e ramos (g) e a relação ramos/folha. Para avaliar a área foliar, foram retiradas folhas do $5^{\circ}$ par (do ápice para a base) de cinco plantas por tratamento, utilizando-se o método da fotocópia.

\section{Análise estatística}

O delineamento experimental foi inteiramente casualizado, com 25 repetições por tratamento (análises de crescimento) e 4 repetições (análises do óleo essencial).

\section{Resultados e Discussão}

Sob $20 \%$ de irradiância, a área foliar mostrouse tendência de ser maior que as plantas cultivadas em pleno sol. Esta tendência de aumento é devido à necessidade da planta realizar maior captação dos raios solares em ambientes menos irradiados (Tabela 2).

Tabela 2. Crescimento de plantas de hortelã-do-campo (Hyptis marrubioides), cultivados em diferentes níveis de irradiância.

\begin{tabular}{|c|c|c|c|c|c|c|c|c|c|}
\hline \multirow[b]{2}{*}{$\begin{array}{l}\text { Irradiância } \\
\qquad(\%)\end{array}$} & \multicolumn{9}{|c|}{ Medidas de crescimento } \\
\hline & $\begin{array}{l}\text { Área foliar } \\
\qquad\left(\mathrm{dm}^{2}\right)\end{array}$ & $\begin{array}{l}\text { Altura } \\
(\mathrm{m})\end{array}$ & $\begin{array}{l}\mathrm{N}^{\mathrm{o}} \mathrm{de} \\
\text { ramos }\end{array}$ & $\begin{array}{l}\text { Diâmetro do } \\
\text { colo }(\mathrm{cm})\end{array}$ & FS folhas $(\mathrm{g})$ & $\begin{array}{l}\text { FS ramos } \\
\quad(\mathrm{g})\end{array}$ & $\begin{array}{l}\text { Relação } \\
\text { ramo/folha }\end{array}$ & $\begin{array}{l}\text { Teor de óleo } \\
\text { essencial (\%) }\end{array}$ & $\begin{array}{c}\text { Rendimento } \\
\text { do óleo } \\
\text { essencial } \\
\text { (g/planta) }\end{array}$ \\
\hline 20 & $7,3 \pm 1,3 \mathrm{a}^{\mathrm{z}}$ & $1,75 \pm 0,50 \mathrm{a}$ & $2,0 \pm 0,22 b$ & $1,7 \pm 0,07 \mathrm{~b}$ & $60 \pm 4,26 \mathrm{c}$ & $70 \pm 0,01 \mathrm{c}$ & $1,3 \pm 0,07 \mathrm{a}$ & $0,33 \pm 0,003 \mathrm{a}$ & $0,2 \pm 0,02 \mathrm{~b}$ \\
\hline 60 & $6,2 \pm 0,8 \mathrm{a}$ & $1,76 \pm 0,07 \mathrm{a}$ & $2,9 \pm 0,34 \mathrm{~b}$ & $2,4 \pm 0,12 \mathrm{a}$ & $240 \pm 16,98 b$ & $190 \pm 0,01 \mathrm{~b}$ & $0,9 \pm 0,05 \mathrm{~b}$ & $0,36 \pm 0,02 \mathrm{a}$ & $0,8 \pm 0,06 \mathrm{ab}$ \\
\hline 100 & $4,6 \pm 0,2 \mathrm{a}$ & $1,45 \pm 0,04 \mathrm{~b}$ & $4,2 \pm 0,50 \mathrm{a}$ & $2,4 \pm 0,18 \mathrm{a}$ & $350 \pm 18,89 \mathrm{a}$ & $310 \pm 0,03 \mathrm{a}$ & $0,9 \pm 0,05 \mathrm{~b}$ & $0,40 \pm 0,04 \mathrm{a}$ & $1,4 \pm 0,21 \mathrm{a}$ \\
\hline
\end{tabular}

${ }^{\mathrm{z}}$ Médias seguidas pela mesma letra na coluna não diferem entre si pelo teste de Tukey ao nível de $5 \%$ de probabilidade. \pm : Erro padrão da média

Quanto ao comprimento da parte aérea, as plantas de $H$. marrubioides apresentaram menor altura quando cultivadas em maior nível de irradiância (100\%), (Tabela 2), devido ao maior investimento fotossintético da planta na produção de ramos. Silva et al. (2006) verificaram em carqueja [Baccharis trimera (Less) DC], Asteraceae, cultivada nos níveis de irradiância 100, 60, 50 e $20 \%$, reduções significativas na altura das plantas à medida que aumentaram os níveis de irradiância.

Letchamo e Gosselin (1996) trabalhando com tomilho (T. vulgaris L.), Lamiaceae, encontraram maior número de brotos em plantas cultivadas sob maior nível de irradiância. Esses resultados estão de acordo com os obtidos no presente estudo.

O diâmetro do caule na altura do colo foi menor no ambiente com menor irradiância (20\%) (Tabela
2). Segundo Naves (1993) o diâmetro do caule pode ser um bom indicador da capacidade assimilatória líquida da planta. Resultados semelhantes foram encontrados por Auken e Bush (1990), para Baccharis neglecta Britt, Asteraceae. Castro, Alvarenga e Gomide (1996), trabalhando com calabura (Muntingia calabura L.), Muntingiaceae, observaram que quanto maior o nível de irradiância, maior o diâmetro do caule das plantas.

Maior acúmulo de fitomassa seca de folhas e ramos, foram detectados quando as plantas foram mantidas em 100\% de irradiância, seguidos, respectivamente, por 60 e 20\% (Tabela 2). A relação ramo/folha foi maior em menor disponibilidade de luz $(20 \%)$, refletindo em maior investimento em área foliar para maior captação de luz. Ao contrário, as plantas recebendo maior disponibilidade de luz 
apresentaram menor área foliar e maior fitomassa seca em ramos (Tabela 2). Auken e Bush (1990) estudando Baccharis neglecta, verificaram que o aumento do nível de irradiância, aumentou significativamente o número de folhas, a produção de fitomasa seca da parte aérea, raízes e total. Scalon e Alvarenga (1993) pesquisando paupereira (Platycyamus regnelli Benth), Fabaceae, observaram que o cultivo de plantas submetidas a diferentes níveis de irradiância não afetaram o diâmetro do caule, fitomassa seca, área foliar e altura, embora tenha havido uma ligeira tendência de maior crescimento naquelas que se encontravam sombreadas. Em tanchagem (P. major), o acúmulo de fitomassa de folhas e o comprimento da parte aérea das plantas foram maiores em níveis mais elevados de irradiância (SOUZA, 1998).

Níveis de irradiância não afetaram o teor de óleo essencial. Ventrela e Ming (2000) observaram $\mathrm{m}$ erva-cidreira (L. alba) maiores acúmulos de fitomassa e teores de óleo essencial em níveis mais elevados de irradiância (30 a 100\%).

Castrillo et al. (2005) observaram em plantas de sambacaita [Hyptis pectinata (L.) Poit.], manjericão (Ocimum basilicum L.), alecrim (Rosmarinus officinalis L.) e sálvia (Salvia officinalis L.), pertencentes à família Lamiaceae, maior acúmulo de fitomassa seca de folhas e açúcares solúveis em cultivo sob maiores níveis de irradiância.

A luz exerceu influência no rendimento do óleo essencial, apresentando-se maior em nível de irradiância mais elevado (100\%), comparado ao nível de 20\% (Tabela 2).

O componente majoritário do óleo essencial de $H$. marrubioides, independente dos níveis de irradiância foi o monoterpeno oxigenado cis-tujona $(37,78 \%)$, seguido pelos hidrocarbonetos sesquiterpênicos (E)-cariofileno (14,93\%), $\alpha$-copaeno $(11,03 \%)$ e $\sigma$-muuroleno $(9,60 \%)$. Entre os sesquiterpenos oxigenados não houve diferenças (Tabela 3).

Tabela 3. Composição química do óleo essencial de plantas de hortelã-do-campo (Hyptis marrubioides), cultivados em diferentes níveis de irradiância.

\begin{tabular}{|c|c|c|c|c|c|c|c|c|c|}
\hline \multirow{2}{*}{$\begin{array}{c}\text { Irradiância } \\
\text { (\%) }\end{array}$} & \multicolumn{8}{|c|}{ Monoterpenos oxigenados } & \multirow{2}{*}{ Total } \\
\hline & cis-tujona & trans-tujona & cis-pinocanfona & neo-3-tujanol & terpinen-4-ol & $\alpha$-terpineol & iso-3-tujanol & 1,8-cineol & \\
\hline 20 & $32,03 \pm 2,83 \mathrm{a}$ & $5,28 \pm 0,50 \mathrm{a}$ & $4,46 \pm 0,14 \mathrm{a}$ & $1,67 \pm 0,19 \mathrm{a}$ & $0,78 \pm 0,05 \mathrm{a}$ & $0,61 \pm 0,30 \mathrm{a}$ & $0,63 \pm 0,09 \mathrm{a}$ & $0,24 \pm 0,12 \mathrm{a}$ & $45,7 \pm 2,9$ \\
\hline 60 & $32,11 \pm 4,05$ a & $5,48 \pm 0,53 \mathrm{a}$ & $4,63 \pm 0,25 \mathrm{a}$ & $1,72 \pm 0,39 \mathrm{a}$ & $0,85 \pm 0,03 \mathrm{a}$ & $0,77 \pm 0,12 \mathrm{a}$ & $0,60 \pm 0,12 \mathrm{a}$ & $0,32 \pm 0,16 \mathrm{a}$ & $46,5 \pm 3,3 \mathrm{a}$ \\
\hline \multirow[t]{3}{*}{100} & $31,19 \pm 1,64$ a & $5,03 \pm 0,19 \mathrm{a}$ & $3,90 \pm 0,37 \mathrm{a}$ & $1,27 \pm 0,36 \mathrm{a}$ & $0,51 \pm 0,26 \mathrm{a}$ & $0,51 \pm 0,25 \mathrm{a}$ & $0,21 \pm 0,21 \mathrm{~b}$ & $0,43 \pm 0,21 \mathrm{a}$ & $42,9 \pm 0,2 \mathrm{a}$ \\
\hline & \multicolumn{8}{|c|}{ Hidrocarbonetos sesquiterpenos } & \multirow{2}{*}{ Total } \\
\hline & (E)-cariofileno & $\alpha$-copaeno & $\sigma$-muuroleno & $\delta$-cadineno & $\alpha$-humuleno & $\beta$-bourboneno & $\sigma$-selineno & germacreno D & \\
\hline 20 & $14,22 \pm 0,80 \mathrm{a}$ & $12,02 \pm 0,23 \mathrm{a}$ & $9,34 \pm 1,09 \mathrm{a}$ & $1,95 \pm 0,07 \mathrm{a}$ & $1,22 \pm 0,08 \mathrm{a}$ & $0,78 \pm 0,06 \mathrm{a}$ & $0,49 \pm 0,28 \mathrm{a}$ & $0,19 \pm 0,19 \mathrm{a}$ & $40,2 \pm 2,5 \mathrm{a}$ \\
\hline 60 & $14,61 \pm 0,77$ a & $10,02 \pm 0,68 \mathrm{a}$ & $9,31 \pm 1,59 \mathrm{a}$ & $1,67 \pm 0,08 \mathrm{~b}$ & $1,21 \pm 0,06 \mathrm{a}$ & $0,89 \pm 0,14 \mathrm{a}$ & $0,29 \pm 0,29 \mathrm{a}$ & $0,27 \pm 0,27 \mathrm{a}$ & $38,3 \pm 2,5 \mathrm{a}$ \\
\hline \multirow[t]{3}{*}{100} & $15,97 \pm 0,81 \mathrm{a}$ & $11,05 \pm 0,77 \mathrm{a}$ & $10,17 \pm 0,84 \mathrm{a}$ & $1,96 \pm 0,05 \mathrm{a}$ & $1,31 \pm 0,03 \mathrm{a}$ & $1,17 \pm 0,15 \mathrm{a}$ & $0,01 \pm 0,00 \mathrm{a}$ & $0,01 \pm 0,00 \mathrm{a}$ & $41,6 \pm 1,7 \mathrm{a}$ \\
\hline & \multicolumn{8}{|c|}{ Sesquiterpenos oxigenados } & \multirow{2}{*}{ Total } \\
\hline & epi-longipinanol & \multicolumn{3}{|c|}{ eudesma-4(15),7-dien-1- $\beta$-ol } & $\begin{array}{l}\text { ido de } \\
\text { riofileno }\end{array}$ & \multicolumn{2}{|c|}{ epóxi-alo-aloaromadendreno } & desconhecido & \\
\hline 20 & $6,49 \pm 0,55 \mathrm{a}$ & $2,82 \pm 0$ & $0,44 \mathrm{a}$ & & $94 \pm 0,11 \mathrm{a}$ & $1,17 \pm 0,14 \mathrm{a}$ & & $0,73 \pm 0,07 \mathrm{a}$ & $12,4 \pm 1,2 \mathrm{a}$ \\
\hline 40 & $6,91 \pm 0,19$ a & $3,08 \pm c$ & $0,46 \mathrm{a}$ & & $21 \pm 0,23 \mathrm{a}$ & $1,46 \pm 0,09 \mathrm{a}$ & & $0,80 \pm 0,10 \mathrm{a}$ & $13,7 \pm 1,1 \mathrm{a}$ \\
\hline 100 & $6,12 \pm 0,83 \mathrm{a}$ & $2,88 \pm 0$ & $0,21 \mathrm{a}$ & & $24 \pm 0,10 \mathrm{a}$ & $1,62 \pm 0,20 \mathrm{a}$ & & $0,97 \pm 0,11 \mathrm{a}$ & $12,9 \pm 1,2 \mathrm{a}$ \\
\hline
\end{tabular}

${ }^{\mathrm{z}}$ Médias seguidas pela mesma letra na coluna não diferem entre si pelo teste de Tukey ao nível de $5 \%$ de probabilidade. \pm : Erro padrão da média. 
A luz não exerceu influência sobre a composição química do óleo essencial. Exceção ocorreu para os compostos iso-3-tujanol, com teores inferiores nas plantas cultivadas a $100 \%$ de irradiância e para o composto $\delta$-cadineno, que apresentou menores teores em plantas cultivadas a $60 \%$ de irradiância (Tabela 3). Peer, Briggs e Langenheim (1999), estudando erva boa [Satureja douglasii (Benth.) Briq.], Lamiaceae, verificaram a presença de muitos monoterpenos em folhas e estes apresentaram diferenças em sua composição, em decorrência dos níveis de irradiação, como exemplo a isomentona.

Em tomilho (T. vulgaris), a composição do óleo essencial foi afetada significativamente por níveis de irradiação. Houve mudanças no conteúdo de fenóis, e em particular, no conteúdo de hidrocarbonetos monoterpênicos do óleo essencial, devido às diferenças em intensidades luminosas. O maior nível de timol foi obtido em maior intensidade luminosa (LETCHAMO et al., 1994; LETCHAMO; GOSSELIN, 1995).

\section{Conclusões}

Acúmulo de fitomassa superior ocorreu em maior intensidade de luz.

O nível de irradiância não influenciou o tero de óleo essencial.

Maior rendimento de óleo essencial foi obtido em plantas cultivadas a pleno sol.

A composição do óleo essencial não foi influenciada pelo nível de luz, exceto para os componentes iso-3-tujanol e $\delta$-cadineno.

\section{Agradecimentos}

Ao CNPq pelo apoio financeiro, em bolsas de Iniciação Científica e de produtividade.

\section{Referências}

ADAMS, R. P. Identification of essential oil components by gas chromatography/quadrupole mass spectroscopy. Carol Stream: Allured, 2001.

AUKEN, O. W. V.; BUSH, J. K. Influence of light levels, soil nutrients, and competition on seedling growth of Baccharis neglecta (Asteraceae). Bulletin of the Torrey Botanical Club, New York, v. 117, n. 4, p. 438-444, Oct./ Dec. 1990.

CASTRILLO, M.; VIZCAINO, D.; MORENO, E.; LATORRACA, Z. Specific leaf mass, fresh:dry weight ratio, sugar and protein contends in species of Lamiaceae from different light environments. Revista de Biologia Tropical, San José, v. 53, n. 1/2, p. 23-28, mar./jun. 2005.

CASTRO, E. M.; ALVARENGA, A. A.; GOMIDE, M. B. Crescimento e distribuição de matéria seca de mudas de calabura (Muntingia calabura L.) submetidas a três níveis de irradiância. Ciência e Agrotecnologia, Lavras, v. 20, n. 3, p. 357-365, jul./set. 1996.

HARLEY, R. M. Evolution and distribution of Eriope (Labiatae) and its relatives in Brasil. In: VANZOLINI, P. E.; HEYER, W. R. (Ed.). Proceedings patterns. Rio de Janeiro: Academia Brasileira de Ciências, 1988, p. 7180.

LETCHAMO,W.; GOSSELIN,A.Effects of supplemental lighting and soil water levels on growth, essential oil contend and composition of two thyme (Thymus vulgaris L) clonal selections. Canadian Journal of Plant Science, Ottawa, v. 75, n. 1, p. 231-238, jan. 1995.

Transpiration, essential oil glands, epicuticular wax and morphology of Thymus vulgaris are influenced by light intensity and water supply. Journal of Horticultural Science, Kent, v. 71, n. 1, p. 123-134, jan. 1996.

LETCHAMO, W.; MARQUARD, R.; HOLZL, J.; GOSSELIN, A. Effects of supply and light intensity on growth and essential oil of two Thymus vulgaris selections. Angewandte Botanik, Berlin, v. 68, n. 3/4, p. 83-88, Oct. 1994.

KUHNT, M.; PROBSTLE, A.; RIMPLER, H.; BAUER, R.; HEINRICH, M. Biological and pharmacological activities and further constituents of Hyptis verticilata. Planta Medica, Stuttgart, v. 61, n. 3, p. 227-232, Jun. 1995. 
NAVES, V. L. Crescimento, distribuição de matéria seca, concentração de clorofilas e comportamento estomático de mudas de três espécies florestais submetidas a diferentes níveis de radiação fotossinteticamente ativa. 1993. Dissertação. (Mestrado em Fisiologia Vegetal) Universidade Federal de Lavras, Lavras.

PEER, W. A.; BRIGGS, W. R.; LANGENHEIM, J. H. Shade-avoidance responses in two common coastal redwood forest species, Sequoia sempervirens (Taxodiaceae) and Satureja douglsii (Lamiaceae), occurring in various light quality environments. American Journal of Botany, Columbus, v. 86, n. 5, p. 640-645, May 1999.

SCALON, S. P. Q; ALVARENGA, A. A. Efeito do sombreamento sobre a formação de mudas de pau-pereira (Platycyamus regnelli Benth). Revista Árvore, Viçosa, v. 17, n. 3, p. 265-270, set./dez. 1993.

SILVA, F. G.; PINTO, J. E. B. P.; CARDOSO, M. G.; NASCIMENTO, E. A.; NELSON, D. L.; SALES, J. F.; MOL, D. J. S. Influence of radiation level on plant growth, yield and quality of essential oil in [Baccharis trimera (Less. ) D. C.]. Ciência e Agrotecnologia, Lavras, v. 30, n. 1, p. 52-57, jan./fev. 2006.
SOUZA, M. M. Crescimento e metabolismo secundário em duas condições de luminosidade e cultura in vitro de Plantago major L. 1998. Tese. (Doutorado em Fitotecnia) - Universidade Federal de Viçosa, Viçosa.

VALIO, I. F. M. Effects of Shading and removal of plant parts on Growth of Trema micrantha Seedlings. Tree Physiology, Victoria, v. 21, n. 1, p. 65-70, Jan. 2001.

VAN DEN DOOL, D. H.; KRATZ, P. D. J. A. Generalization of the retention index system including linear temperature programmed gas-liquid partition chromatography. Journal of Chromatogrography, Amsterdam, v. 11, n. 4, p. 463-471, 1963.

VENTRELA, M. C.; MING, L. C. Produção de matéria seca e óleo essencial em folhas de erva-cidreira sob diferentes níveis de sombreamento e épocas de colheita. Horticultura Brasileira, Brasília, v. 18, p. 972-974, 2000. Suplemento.

VILELA, A. E.; RAVETTA, D. A. The effect of radiation on seedling growth and physiology in four Species of Prosopis L. (Mimosaceae). Journal of Arid Environments, London, v. 44, n. 4, p. 415-423, Apr. 2000.

WILLIS, J. C. Dictionary of flowering plants and ferns. London: Columbia University Press, 1973. 
